Kumawula, Vol. 2, No.2, Agustus 2019, Hal 175 - 182 DOI:http://10.24198/kumawula.v1i3.24565

ISSN 2620-844X (online)

Tersedia online di http://jurnal.unpad.ac.id/kumawula/index

\title{
EDUKASI ANAK BINAAN SANGGAR WARINGIN TENTANG BULLYING MELALUI PENYULUHAN DENGAN METODE SOSIODRAMA
}

\author{
Achmad Faidz Mufidi' ${ }^{1}$, Tiara Salsabilla ${ }^{2}$, Muthia Fadhila Khairunnisa ${ }^{3}$, Galuh Hanesty \\ Gunawan $^{4}$, Hery Wibowo \\ ${ }^{1,2,3,4}$ Mahasiswa Ilmu Kesejahteraan Sosial Universitas Padjadjaran, ${ }^{5}$ Dosen Ilmu Kesejahteraan Sosial \\ Universitas Padjadjaran \\ achmad18005@mail.unpad.ac.id', tiara18011@mail.unpad.ac.id²,muthia18001@mail.unpad.ac.id², \\ galuh18003@mail.unpad.ac.id ${ }^{4}$,hery.wibowo@unpad.ac.id ${ }^{5}$
}

\begin{abstract}
ABSTRAK
Sanggar Waringin merupakan rumah singgah bagi anak jalanan di lingkungan rentan dekat Stasiun Bandung. Penelitian research and development ini bertujuan untuk melakukan uji coba metode sosiodrama yang dapat digunakan dalam mengedukasi anak yang membutuhkan perlindungan khusus tentang bullying. Metode sosiodrama digunakan berdasarkan Social Learning Theory yang menyatakan bahwa perkembangan perilaku manusia terbentuk berdasarkan apa yang mereka alami di kehidupan. Sampel yang digunakan adalah 15 anak binaan Sanggar Waringin dengan rentang umur 5-13 tahun. Hasil penelitian ini menunjukkan bahwa sosiodrama dapat menjadi salah satu metode yang digunakan untuk memberikan penyuluhan kepada anak-anak, dengan catatan perlu ada visualisasi terlebih dahulu agar anak dapat lebih paham tentang materi yang diberikan.
\end{abstract}

Kata Kunci: Sosiodrama; Social Learning Theory; Bullying

\section{EDUCATION OF THE SANGGAR WARINGIN CHILDREN ABOUT BULLYING THROUGH COUNCELING WITH THE SOSIODRAMA METHOD}

\begin{abstract}
Sanggar Waringin is a place for street children that are in a vulnerable environment near Bandung Station. This research aims to test the sociodrama method that can be used for educating children in need of special protection about bullying. Sociodrama is used based on the Social Learning Theory which states that the development of human behavior is formed based on their life experiences. 15 children in Sanggar Waringin around the ages of 5-13 years old were used as the sample. The results of this study indicates that sociodrama can be used as one of the methods that provide counseling to children, but there is a visualization needed in advance so the children can understand the material well.
\end{abstract}

Keywords: Sociodrama; Social Learning Theory; Bullying

\section{PENDAHULUAN}

Masa kanak-kanak merupakan fase terpenting dalam pembentukan moral, kepribadian, dan 
fungsi-fungsi anak. Kartini Kartono (1979) dalam karyanya, Psikologi Anak, menyebutkan, tahap yang disebut dengan periode intelektual (6-12 tahun) merupakan masa perkembangan anak yang sangat pesat. Dengan begitu, orang tua memiliki peran penting untuk mengiringi masa tumbuh kembang anak, karena anak yang membutuhkan perlindungan khusus (children in need of special protection) dalam mengeksplorasi lingkungan sekitarnya.

Berdasarkan Undang-Undang Nomor 23 Tahun 2002 tentang Perlindungan Anak, “Anak yang membutuhkan perlindungan khusus adalah anak dalam situasi darurat, anak yang berhadapan dengan hukum, anak dari kelompok minoritas dan terisolasi, dan anak tereksploitasi, mencakup eksploitasi ekonomi dan/atau seksual anak yang diperdagangkan, anak yang menjadi korban penyalahgunaan narkotika, alkohol, psikotropika, dan zat adiktif lainnya (napza), anak korban penculikan, penjualan dan perdagangan, anak korban kekerasan baik fisik dan/atau mental, anak yang menyandang cacat, dan anak korban perlakuan salah dan penelantaran."

Bullying merupakan bibit awal terjadinya perilaku kekerasan atau kejahatan. Bullying sendiri adalah perilaku agresif yang dapat mengakibatkan tekanan pada pihak yang lebih lemah dan tidak mampu membela serta mempertahankan dirinya. Bullying tidak hanya tentang tindakan yang dilakukan, tetapi juga dampak yang ditimbulkan atas tindakan tersebut bagi korban.

Dalam teori psikososial oleh Erik Erikson, lingkungan sosial seorang individu memiliki pengaruh terhadap pembentukan kepribadian. Sehingga, perilaku-perilaku yang dicerminkan oleh orang dewasa di lingkungan Sanggar Waringin dapat memengaruhi perilaku anak-anak. Ketika perilaku yang dicerminkan adalah perilaku yang baik, maka kemungkinan besar anakanak akan mengimitasi perilaku baik tersebut. Sedangkan ketika perilaku yang dicerminkan merupakan perilaku kasar dan keras, maka akan memberikan dampak buruk terhadap perilaku anak. Jika tidak diberi pemahaman lebih lanjut, anak-anak dapat menerapkan perilaku kasar tersebut kepada temannya yang berujung pada bullying. Namun, tidak menutup kemungkinan bagi anak-anak di Sanggar Waringin untuk menjadi korban dari bullying. Perbedaan kelas dalam aspek ekonomi yang dilakukan oleh kelompok atau individu yang mendominasi individu atau kelompok lain yang lebih subordinat, menjadi faktor bullying. Hal tersebut memungkinkan anak-anak Sanggar Waringin menjadi korban bullying di sekolah mereka yang terdiri dari anakanak yang berasal dari berbagai kelas ekonomi.

Selain di lingkungan sekolah, anak-anak tersebut juga dapat menjadi korban bullying di lingkungan tempat tinggal mereka. Seperti yang telah dipaparkan sebelumnya, perilaku kasar yang mungkin timbul di lingkungan sosial mereka dapat menjadi pemicu untuk ditiru. Sehingga, mungkin saja bagi anak-anak di sana untuk berperilaku demikian terhadap 
sesamanya.

Jurnal ini akan membahas lebih lanjut tentang tahapan edukasi bagi anak binaan di Sanggar Waringin tentang bullying. Metode yang dipakai adalah contextual teaching and learning untuk mendorong self-directed learning menggunakan sociodrama. Proses pelaksanaan dan hasil dari kegiatan edukasi tersebut disajikan dalam artikel ini.

\section{TINJAUAN PUSTAKA}

\section{Social Learning Theory untuk Edukasi tentang Bullying}

Perilaku seorang individu berasal dari proses pembelajaran yang ia lalui. Pengalaman hidup seorang individu menjadi faktor utama pembentukan atau pengembangan kepribadian dan perilaku. Seorang anak berperilaku dan memodifikasi perilakunya berdasarkan apa yang mereka temui dari lingkungan fisik dan sosialnya.

Berbeda dengan tahapan yang dijelaskan oleh Freud (psikoanalisis) dan Piaget (kognitif) dalam perkembangan psikologi manusia. Dalam Social Learning Theory, Albert Bandura percaya bahwa perkembangan manusia (perilakunya) terbentuk berdasarkan apa yang mereka alami di kehidupan. Eksperimennya menggunakan Bobo Doll menunjukan bahwa seorang anak dapat mengikuti apa yang seorang model lakukan. Ketika seorang model memberikan perilaku abusive kepada Bobo Doll, anak tersebut memberikan perilaku yang abusive juga. Bahkan mereka memodifikasi perilaku dengan menggunakan tembakan yang ditodongkan ke arah Bobo Doll. Padahal sang model tidak memberikan contoh demikian. Sedangkan ketika seorang model lainnya menunjukan perilaku yang lembut dan tidak kasar, anak-anak yang menyaksikannya juga berperilaku tidak kasar.

Anak-anak memperoleh kemampuan-kemampuan baru, informasi, atau mengubah perilaku lama, dengan menyaksikan anak lain atau orang dewasa. Bandura percaya bahwa pembelajaran secara dominan diperoleh dari pembelajaran observasional (observational learning) dan instruksi, serta perilaku trial-and-error tidak berpengaruh secara signifikan.

Perilaku yang dicerminkan oleh keluarga, lingkungan pertemanan, dan kehidupan masyarakat, dapat memengaruhi seorang anak dalam berperilaku.

Anak-anak yang diibaratkan sebagai suatu lembaran kertas yang harus diisi, maka mereka cenderung bersifat mudah terpengaruhi dan mengimitasi. Dengan begitu, ketika anak-anak melihat perilaku yang menyimpang, akan terdapat kemungkinan bagi anak-anak tersebut untuk meniru hal tersebut. Sama halnya dengan perilaku bullying, yang dapat menjadi contoh buruk dalam proses eksplorasi dunia anak. Pengaruh-pengaruh tersebut dapat tertanam dalam 
kepribadian seorang anak apabila terjadi reinforcement (penguatan). Bentuk-bentuk dari reinforcement tersebut dapat berupa pembiaran, pemujian, ataupun pemberian penghargaan. Pengaruh tayangan kurang mendidik di televisi, kekerasan dalam rumah tangga, perilaku kasar lingkungan masyarakat sekitar, bahkan teman sepermainan, dapat memengaruhi seorang anak untuk melakukan bullying. Sehingga, Social Learning Theory merupakan pendirian yang tepat dalam membahas perilaku bullying di kalangan anak-anak.

\section{Penggunaan Sosiodrama dalam Edukasi tentang Bullying}

Sosiodrama merupakan teknik mengajar yang dapat dilakukan guru terhadap muridnya untuk melakukan kegiatan bermain peran tertentu seperti ada yang ada di kehidupan sosial masyarakat (Kurniawan \& Pranowo, 2018). Kellerman (2007) mengemukakan, "Sociodrama is an experiential group-as-a-whole procedure for social exploration and intergroup conflict transformation", mengindikasikan bahwa metode sosiodrama merupakan metode eksperimental kelompok untuk transformasi sosial dan konflik.

Metode sosiodrama dapat digunakan untuk mengedukasi kelompok dalam berbagai hal, sesuai topik atau tema dari sosiodrama tersebut. Contohnya adalah dengan bermain peran tentang Perang Dunia, di mana ada pihak yang berperan sebagai penyerang, korban, tim medis, maupun hanya sebagai saksi. Moreno, pencetus metode psikodrama dan sosiometri yang mengembangkan metode sosiodrama di era Perang Dunia II berharap, dengan memerankan kembali konflik antarkelompok dengan memiliki perwakilan dari tiap kelompok berbeda yang memerankan satu sama lain, orang-orang dapat memperoleh perspektif tentang pemahaman, perdamaian, dan tatanan sosial baru (Marineau, 1989; Kellerman, 2007).

Menggunakan metode sosiodrama, anak-anak bisa mendapat pandangan baru terkait perilaku bullying, dari sisi pelaku, korban, maupun saksi; sejalan dengan anggapan Social Learning Theory di mana anak-anak belajar banyak dari lingkungan sosialnya.

\section{METODE}

Metode yang digunakan dalam penelitian ini adalah Research and Development, yakni metode untuk menghasilkan produk tertentu, serta menguji keektifan produk itu (Sugiyono, 2009). Terdapat lima tahapan inti dalam pelaksanaan edukasi tentang bullying kepada anak binaan Sanggar Waringin. Tahapan ini diambil berdasarkan metode pelaksanaan sosiodrama, yang kemudian dimodifikasi untuk digabungkan dengan unsur-unsur edukasi tentang bullying.

Pertama, briefing dan pembagian peran kepada peserta. Tahap awal ini meliputi pemberian pemahaman tentang apa itu bullying, dampak bullying, hingga penjelasan terkait betapa 
pentingnya memiliki pemahaman tentang bullying. Kemudian, ada pembagian peran kepada peserta. Terdapat lima kartu peran yang akan dibagikan kepada lima kelompok peserta; pelaku, korban yang tidak membela diri, korban yang membela diri, saksi yang diam, dan saksi yang menolong korban. Peran korban dan saksi masing-masing terbagi menjadi dua conditional stimulus, guna memperkenalkan kepada para peserta terkait opsi yang dapat mereka lakukan seandainya menjadi korban atau saksi tindakan bullying.

Kedua, pelaksanaan sosiodrama sesi 1. Di tahap ini, peserta yang mendapat peran, baik sebagai pelaku, korban, atau saksi, bermain peran sesuai hasil briefing yang ada pada tahap sebelumnya. Sementara, peserta lain menonton dramanya.

Ketiga, diskusi. Pada tahap ini, para penonton diharapkan bisa mengungkapkan pendapat terkait sosiodrama yang dimainkan, serta memahami mana tindakan yang semestinya mereka lakukan berdasarkan conditional stimulus yang diberikan.

Keempat, pelaksanaan sosiodrama sesi 2 . Berbeda dengan sesi 1, di bagian ini, hanya terdapat tiga kartu peran; pelaku, korban, dan saksi. Korban dan saksi tidak diberi conditional stimulus seperti sebelumnya. Anak-anak yang berperan pada sesi ini adalah para penonton di sesi pertama. Setelah diskusi, mereka sudah mengetahui perilaku apa yang semestinya dilakukan jika menjadi korban atau saksi. Maka, di sesi ini, mereka memberikan unconditional response berdasarkan stimulus yang diberikan pelaku.

Kelima, kesimpulan. Seperti tahap ketiga, terdapat diskusi terkait sosiodrama yang ditampilkan. Fokusnya ada pada unconditional response yang diberikan oleh pemeran korban maupun saksi, serta mendiskusikan jika bullying terjadi di lingkungan sekitar mereka.

\section{HASIL DAN PEMBAHASAN}

Sanggar Waringin merupakan rumah singgah yang berada di antara pusat keramaian di kota Bandung yakni Terminal Ciroyom dan Stasiun Bandung, tepatnya di Jl. Stasiun Selatan No. 29, Bandung, Jawa Barat. Rumah singgah ini merupakan tempat yang mewadahi anak-anak lingkungan sekitar khususnya untuk anak jalanan dengan fasilitas yang disediakan seperti perpustakaan, ruang belajar atau diskusi, dan tempat bermain yang nyaman bagi mereka (Almaliah, 2016). Diinisiasi oleh seorang mantan preman yang bernama Pak Ana Sumarna yang tergerak hatinya saat melihat kurangnya fasilitas ruang bermain dan belajar, serta tingginya angka anak putus sekolah di lingkungan Stasiun Selatan, Kota Bandung. Tidak hanya menjadi rumah baca, Sanggar Waringin juga menjadi rumah singgah bagi anak-anak jalanan dan menjadi tempat untuk melakukan kegiatan positif bagi warga sekitar. 
Sebenarnya, Pak Ana menggagas untuk mendirikan Sanggar Waringin tersebut sejak tahun 1997. Sanggar Waringin didirikan karena keprihatinan pak Ana melihat anak-anak jalanan yang bermain di sekitar stasiun yang mana banyak preman dan pekerja seks komersial. Faktanya, di dekat Sanggar Waringin, terdapat salah satu hotel tempat prostitusi yang masih berjalan hingga saat ini, yang mana akan berdampak buruk terhadap psikologi anak-anak tersebut ditambah lagi dengan situasi lingkungan terminal yang penuh dengan kekerasan sangat tidak baik bagi tumbuh kembang anak. Maka, salah satu alasan adanya Sanggar Waringin ialah agar anak-anak yang tumbuh di daerah tersebut bisa teredukasi dengan baik dan menjadi tempat untuk anakanak bermain sambil belajar.

Jumlah anak binaan sanggar waringin saat ini sebanyak 203 anak, yang mana 40\% diantaranya adalah anak jalanan dan anak-anak yang tinggal di sekitar sanggar waringin, dan 60\% nya adalah anak terlantar. Range usia anak-anak di Sanggar waringin sangat beragam antara 5-12 tahun. Kebanyakan anak binaan berasal dari keluarga status sosial ekonomi rendah.

\section{Hasil}

Hasil yang penulis dapatkan setelah melakukan metode sosiodrama dalam mengedukasi bullying pada anak-anak usia Sekolah Dasar (SD) di Sanggar Waringin kurang sesuai dengan apa yang diharapkan. Setelah melakukan metode sosiodrama, ternyata masih ada anak yang belum memahami perilaku bullying. Pada diskusi akhir, beberapa anak masih bingung dan memilih untuk diam ketika mereka menjadi korban bullying. Akhirnya, penulis memberikan penjelasan kembali tentang apa yang seharusnya mereka lakukan ketika menjadi korban maupun saksi dari perilaku bullying. Salah satu anak yang telah berhasil memahami perilaku bullying melalui sosiodrama yang digunakan merupakan murid kelas satu sekolah dasar.

\section{Pembahasan}

Metode sosiodrama yang telah dilaksanakan dalam mengedukasi bullying kepada anak-anak usia SD di Sanggar Waringin berjalan kurang efektif dan tidak sesuai harapan. Hal tersebut dikarenakan terbatasnya waktu, ruangan, peserta, serta kurangnya persiapan yang matang. Sebelum memulai materi, penulis melakukan pendekatan dengan bermain bersama. Lalu, penulis memulai tahapan pelaksanaan sociodrama dengan melakukan briefing dan pembagian peran. Pembagian peran kepada peserta didasarkan pada lima kartu; pelaku, korban yang tidak membela diri, korban yang membela diri, saksi yang diam, dan saksi yang menolong. Pada tahap ini, penulis juga memberikan pemahaman tentang apa itu bullying, dampak bullying, hingga penjelasan terkait betapa pentingnya memiliki pemahaman tentang bullying. 
Sayangnya, pada tahap ini penulis tidak memberikan video kepada peserta tentang contoh kondisi yang akan terjadi. Padahal, sebenarnya pemberian video dapat membantu mengedukasi peserta agar lebih mudah memahami maksud yang dituju.

Sosiodrama yang telah dilakukan hanya berjalan satu kali dan dimulai dengan memberikan kartu peran kepada enam orang peserta. Mereka kemudian berperan sesuai dengan apa yang telah diberikan saat briefing sedangkan peserta lainnya menjadi penonton. Saat melakukan peran, ternyata peserta masih bingung dan kesulitan untuk memahami apa yang harus mereka lakukan sehingga sociodrama berjalan dengan kurang efektif. Para peserta juga masih malumalu untuk berperan sesuai kartu yang telah diberikan. Penulis pun memberikan arahan kembali kepada peserta agar mereka bisa berperan sesuai dengan kartu yang diberikan.

Setelah sesi tersebut, penulis melakukan diskusi bersama semua peserta termasuk pemain dan penonton terkait sosiodrama yang telah ditampilkan. Pada diskusi tersebut, penulis meminta tanggapan dari pemain tentang apa yang mereka rasakan saat bermain peran. Penulis juga meminta tanggapan dari para peserta tentang kasus yang kami tampilkan, apakah hal tersebut baik merupakan perbuatan terpuji, dan apa yang seharusnya mereka lakukan. Diskusi ini berjalan dengan tidak formal, penulis berusaha untuk membangun suasana yang menyenangkan agar peserta merasa nyaman dalam memberikan tanggapannya.

Berdasarkan diskusi yang dilakukan, ternyata masih banyak peserta yang memilih untuk diam saat mereka menjadi korban atau saksi bullying. Padahal, seharusnya mereka bisa melawan dan melaporkan ketika menjadi korban. Sedangkan saksi seharusnya membantu dan melaporkan kejadian yang dilihatnya. Pada pelaksanaan tersebut penulis kembali menjelaskan tentang bullying dan perilaku yang seharusnya mereka lakukan ketika kejadian. Penulis juga menghimbau mereka untuk tidak melakukan bullying karena perilaku tersebut merupakan perilaku yang tercela.

\section{SARAN DAN REKOMENDASI}

Untuk mencapai kesempurnaan dalam metode yang telah dilaksanakan, Penulis merekomendasikan beberapa saran, sebagai berikut:

1. Sebelum melakukan eksekusi dari sosiodrama, perlu dilakukan persiapan yang lebih matang. Mulai dari menetapkan jumlah dan target usia anak.

2. Pada tahap awal sebelum pembagian peran, seharusnya anak-anak diperlihatkan video mengenai bullying terlebih dahulu. Sehingga mereka memiliki bayangan mengenai bagaimana melakukan perannya. 
3. Untuk mengukur secara efektif apakah output yang didapatkan sesuai dengan harapan atau tidak, diperlukan parameter atau indikator yang jelas (seperti mini quiz atau pretest dan post-test)

4. Perlu dilakukan di tempat yang lebih kondusif, sehingga anak-anak bisa fokus terhadap jalannya sosiodrama.

\section{DAFTAR PUSTAKA}

Almaliah, N. (2016). Studi Deskriptif Children Well Being Pada Anak Jalanan Di Rumah Sanggar Waringin Bandung.

Kartono, K. (1979). Psikhologi Anak. Bandung: Alumni Bandung.

Kellerman, P. F. (2007). Sociodrama and Collective Trauma. London: Jessica Kingsley Publishers.

Kurniawan, D. E., \& Pranowo, T. A. (2018). Bimbingan Kelompok dengan Teknik Sosiodrama sebagai Upaya Mengatasi Perilaku Bullying di Sekolah. Jurnal Bimbingan dan Konseling Terapan, 2(1).

Miller, P. H. (1993). Theories of Developmental Psychology. New York: W. H. Freeman and Company.

Novalia, R. (2016, September 23). Dampak Bullying terhadap Kondisi Psikososial Anak di Perkampungan Sosial Pingit. Diperoleh dari Institutional Repository UIN Sunan Kalijaga Yogyakarta: http://digilib.uin-suka.ac.id/22057/

Pemerintah Indonesia. 2002. Undang-Undang Nomor 23 Tahun 2002 tentang Perlindungan Anak. Lembaran RI Tahun 2002 Nomor 109. Jakarta: Sekretariat Negara.

Sugiyono. (2009). Metode Penelitian Pendidikan Pendekatan Kuantitatif, Kualitatif, dan R \& $D$. Bandung: Alfabeta.

Ulfianti, D. (2013). Proses bimbingan belajar anak terlantar dalam merubah perilaku: Penelitian di lembaga rumah perlindungan anak Wahana Karya Bakti Pertiwi Jl. Stasiun Selatan No. 29 Kota Bandung (Doctoral dissertation, UIN Sunan Gunung Djati Bandung). 